\title{
Testing of the Trim Tab Parametric Model in NASA Langley's Unitary Plan Wind Tunnel
}

\author{
Kelly J. Murphy ${ }^{1}$, Anthony N. Watkins ${ }^{2}$, Ashley M. Korzun ${ }^{3}$, Karl T. Edquist ${ }^{4}$ \\ NASA Langley Research Center, Hampton, VA 23681, USA
}

\begin{abstract}
In support of NASA's Entry, Descent, and Landing technology development efforts, testing of Langley's Trim Tab Parametric Models was conducted in Test Section 2 of the NASA Langley Unitary Plan Wind Tunnel. The objectives were to generate quantitative aerodynamic data and qualitative surface pressure data for computational validation and aerodynamic database development. Six-component force and moment data were measured on 38 unique blunt-body trim tab configurations at Mach numbers of 2.5, 3.5, and 4.5, angles of attack from $-4^{\circ}$ to $+20^{\circ}$, and angles of sideslip from $0^{\circ}$ to $+8^{\circ}$. Configuration parameters investigated in this study were forebody shape, tab area, tab cant angle, and tab aspect ratio. Pressure sensitive paint was used to provide qualitative surface pressure distributions for a subset of these flow and configuration variables. Over the range of parameters tested, the effects of varying tab area and tab cant angle were found to be much more significant than varying tab aspect ratio relative to key aerodynamic performance requirements. Qualitative surface pressure data supported the integrated aerodynamic data and provided information to aid in future analyses of localized phenomena for trim tab configurations.
\end{abstract}

\section{Nomenclature}

$\begin{array}{llll}\mathrm{AF} & \text { Axial force, lbf } & \mathrm{RM} & \text { Rolling moment, in-lbf } \\ \mathrm{CA} & \text { Axial-force coefficient, } \mathrm{AF} / \mathrm{q}_{\infty} \mathrm{S}_{\mathrm{ref}} & \mathrm{SF} & \text { Side force, lbf } \\ \mathrm{C}_{\mathrm{D}} & \text { Drag-force coefficient, } \mathrm{C}_{\mathrm{A}} \cos \alpha+\mathrm{C}_{\mathrm{N}} \sin \alpha & \mathrm{S}_{\mathrm{ref}} & \text { Model reference area, in }{ }^{2} \\ \mathrm{C}_{\mathrm{l}} & \text { Rolling-moment coefficient, } \mathrm{RM} / \mathrm{q}_{\infty} \mathrm{S}_{\mathrm{ref}} \mathrm{L}_{\mathrm{ref}} & \mathrm{T} \mathrm{T} & \text { Freestream total temperature, }{ }^{\circ} \mathrm{R} \\ \mathrm{C}_{\mathrm{L}} & \text { Lift-force coefficient, } \mathrm{C}_{\mathrm{N}} \cos \alpha-\mathrm{C}_{\mathrm{A}} \sin \alpha & \mathrm{X} & \text { Body-axis reference coordinate, in } \\ \mathrm{C}_{\mathrm{m}} & \text { Pitching-moment coefficient, } \mathrm{PM} / \mathrm{q}_{\infty} \mathrm{S}_{\mathrm{ref}} \mathrm{L}_{\mathrm{ref}} & \mathrm{Y} & \text { Body-axis reference coordinate, in } \\ \mathrm{C}_{\mathrm{n}} & \text { Yawing-moment coefficient, } \mathrm{YM} / \mathrm{q}_{\infty} \mathrm{S}_{\mathrm{ref}} \mathrm{L}_{\mathrm{ref}} & \mathrm{YM} & \text { Yawing moment, lbf } \\ \mathrm{C}_{\mathrm{N}} & \text { Normal-force coefficient, } \mathrm{NF} / \mathrm{q}_{\infty} \mathrm{S}_{\mathrm{ref}} & \mathrm{Z} & \text { Body-axis reference coordinate, in } \\ \mathrm{C}_{\mathrm{P}} & \text { Static pressure coefficient, }\left(\mathrm{p}-\mathrm{p}_{\infty}\right) / \mathrm{q}_{\infty} & \alpha & \text { Angle of attack, deg } \\ \mathrm{C}_{\mathrm{Y}} & \text { Side-force coefficient, } \mathrm{SF} / \mathrm{q}_{\infty} \mathrm{S}_{\mathrm{ref}} & \beta & \text { Angle of sideslip, deg } \\ \mathrm{d} & \text { Model diameter, in } & & \\ \mathrm{L}_{\mathrm{ref}} & \text { Reference length, in } & & \\ \mathrm{L} / \mathrm{D} & \text { Lift-to-Drag Ratio } & & \\ \mathrm{M}_{\infty} & \text { Freestream Mach number } & & \\ \mathrm{NF} & \text { Normal force, lbf } & & \\ \mathrm{p} & \text { Model surface static pressure, } \mathrm{psf} & & \\ \mathrm{p}_{\infty} & \text { Freestream static pressure, } \mathrm{psf} & & \\ \mathrm{PM} & \text { Pitching Moment, in-lbf } & & \\ \mathrm{P}_{\mathrm{T}} & \text { Freestream total pressure, } \mathrm{psf} & & \\ \mathrm{q}_{\infty} & \text { Freestream dynamic pressure, } \mathrm{psf} & & \\ \mathrm{Re} & \text { Freestream unit Reynolds number, } \mathrm{ft} & & \end{array}$

\footnotetext{
${ }^{1}$ Aerospace Engineer, Aerothermodynamics Branch, M/S 408A, kelly.j.murphy@ nasa.gov.

2 Aerospace Engineer, Advanced Sensing and Optical Measurement Branch, M/S 493. anthony.n.watkins@ nasa.gov.

3 Aerospace Engineer, Atmospheric Flight and Entry Systems Branch, M/S 489. ashley.m.korzun@ nasa.gov, AIAA Member.

4 Aerospace Engineer, Atmospheric Flight and Entry Systems Branch, M/S 489. karl.t.edquist@ nasa.gov, Senior AIAA Member.
} 


\section{Introduction}

NASA's Space Technology roadmap includes focused Entry, Descent, and Landing (EDL) technology activities to enable both increased mass delivery and more robust landing capabilities for future planetary missions. ${ }^{1}$ The current state-of-the-art, the 2011 Mars Science Laboratory (MSL) mission, flew a guided trajectory using a ballast mass to achieve an offset center-of-gravity (CG) and maintain a trim angle of attack near 16 degrees. Because the cruise stage was spin-balanced during interplanetary transit, an additional counter-balance mass (ejected prior to atmospheric entry) was also required to offset the trim ballast. These combined masses represent $325 \mathrm{~kg}$ of sacrificed payload. Trim tabs are deployable aerodynamic surfaces capable of trimming a vehicle to a non-zero angle of attack with minimal or no radial CG offset. Thus, trim tabs could provide a mass-savings alternative to the current practice of using CG-offset ballast mass to maintain the trim angle required for lift (increased payload mass) and guidance (precision targeting). In a preliminary analysis done by the recent Mars Science Laboratory Improvements (MSL-I) study, ${ }^{2}$ a trim-tab concept (Figure 1) enabled a $1464 \mathrm{~kg}$ landed mass, as opposed to only $1230 \mathrm{~kg}$ for the baseline configuration with ballast mass. The trim tabs thus provided a mass savings of $235 \mathrm{~kg}$. To put these two results into perspective, the mass of the Mars Exploration Rovers were $185 \mathrm{~kg}$ each. The mass savings benefit of a

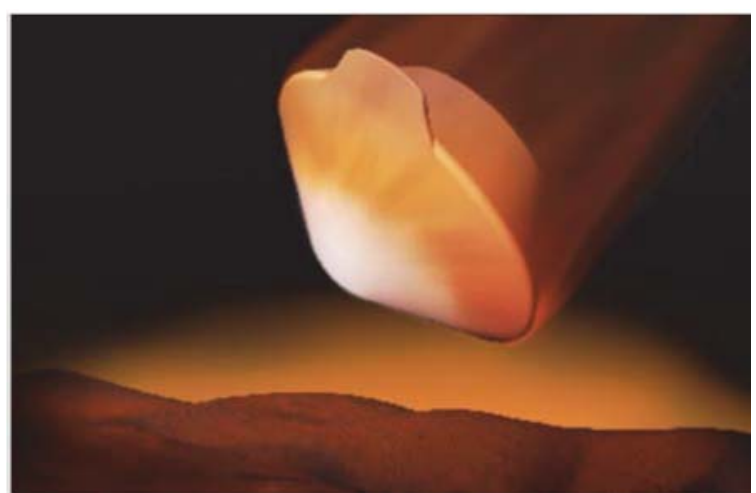

Figure 1. Artist's concept of proposed planetary trim tab configuration. trim tab is of the same order as a small science mission payload. EDL at other planetary destinations besides Mars could also benefit from the use of trim tabs if a non-zero angle of attack is desired.

Current and previous research has long pointed to trim tabs affording a very effective method to increase landed mass for planetary entry for both blunt and slender bodies. Experimental investigations of trim tab configurations occurred as early as 1961 for Mercury-type and Apollo-type entry capsules. ${ }^{3-5}$ More recent work has examined the feasibility of trim tabs for robotic Mars lander missions through system analysis, ${ }^{6-8}$ wind tunnel testing, ${ }^{9,10}$ and computational aerodynamic analysis. ${ }^{9-12}$ High fidelity aerodynamic analyses were not used to generate aerodynamic/aerothermodynamic databases due to a lack of parametric experimental data with which to anchor and validate computational tools. The Mars Surveyor 2001 work $^{9}$ investigated a single placement of a trim tab of 3 different sizes at Mach 6 test conditions. An experimental aerodynamic test conducted by the first author ${ }^{10}$ for the Mars 2007 Smart Lander (which later became MSL) generated data for tab parametrics in the supersonic test regime $\left(\mathrm{M}_{\infty}=2.5\right.$ to $\left.\mathrm{M}_{\infty}=4.5\right)$ and provided a valuable set of comparison data for current work.

In order to obtain the data required to validate the expected benefits of aerodynamic trim tabs, supersonic aerodynamic data were obtained for a range of trim tab parametrics. The effects of trim tabs with various areas, aspect ratios and deflection angles on aerodynamics and aeroheating will be examined for several entry-vehicle configurations. A combination of wind tunnel testing, Computational Fluid Dynamics (CFD) flow field analyses, flight dynamics simulations, and mechanical and thermal design is proposed to evaluate trim tab performance. The results can used to develop candidate trim-tab designs for future exploration missions. The goal is to advance trim tab design concepts from a Technology Readiness Level (TRL) of 3 to a TRL of 6, where the knowledge base is sufficient for flight-testing. The first experimental aerodynamic test program for trim tab database development is described herein.

\section{Objectives}

A four-week test program to generate static aerodynamic data for various trim tab configurations at supersonic conditions was executed in the Unitary Plan Wind Tunnel (UPWT) at the NASA Langley Research Center (LaRC). The objectives of the test program were as follows:

(1) Generate longitudinal static aerodynamic data for Trim Tab Parametric Model (TTPM) at supersonic test conditions for a range of attitude, configuration, and flow field parametrics to support aerodynamic database development for trim tabs. To accomplish this objective, 38 unique blunt-body trim tab 
models were designed and fabricated for testing in the LaRC UPWT. Longitudinal force and moment data were generated using a standard six-component strain-gage force and moment balance.

(2) Generate complementary surface static pressure data for the TTPM configurations at supersonic test conditions for a range of attitude, configuration, and flow field parametrics. Pressure sensitive paint (PSP) techniques were used to generate global surface pressure distributions on a subset of the force and moment models. Virtual Diagnostic Interface (ViDI) simulation capabilities were used to facilitate PSP installation and data collection. Discrete surface pressure data were generated to anchor the PSP results via single static pressure orifices on both the windward and leeward sides of the model. These global pressure distributions will be used in a qualitative sense to enhance understanding of the comparison of experimental results with CFD solutions.

\section{Configuration Description}

Typical of planetary entry configurations, the blunt sphere-cone (S-C) shape, shown in Figure 2, was chosen as the basis for the TTPM. Four unique forebody configurations were modeled: 70-deg, 60-deg, and 50-deg sphere-cones and the Apollo shape. For the 6inch diameter models fabricated for these tests, the nose radius of the three sphere-cone models is 1.5 inches (a single 60-deg configuration was tested with a 0.75 -inch nose radius) and the shoulder radius is 0.15 inches. The Apollo forebody geometry has a nose radius of 7.11 inches and a shoulder radius of 0.30 inches. As shown in Figure 2, the cant angle of a tab is defined relative to the forebody geometry. A cant angle of 0 degrees is parallel to the forebody angle and a cant angle of 90 degrees is normal to the forebody. Tab areas are defined as a percentage of projected model frontal area. Tab aspect ratio, the ratio of width to length of the tab, was another parameter varied for the TTPM. The lower image in Figure 2 shows a two-tab configuration and the angular location convention. A description of physical models tested and the matrix of executed parametrics are found in subsequent sections of this paper.

\section{Experimental Program}

\section{Models and Support Hardware}

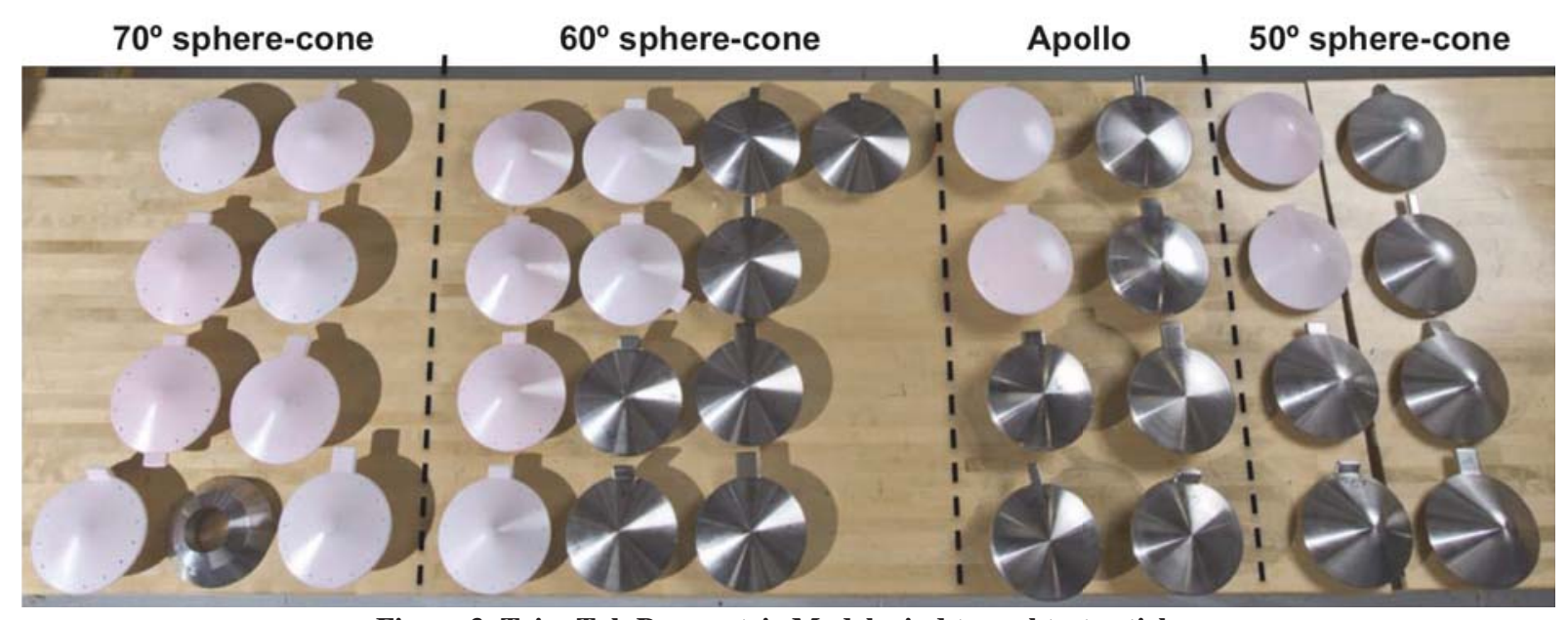

Figure 3. Trim Tab Parametric Model wind tunnel test articles.

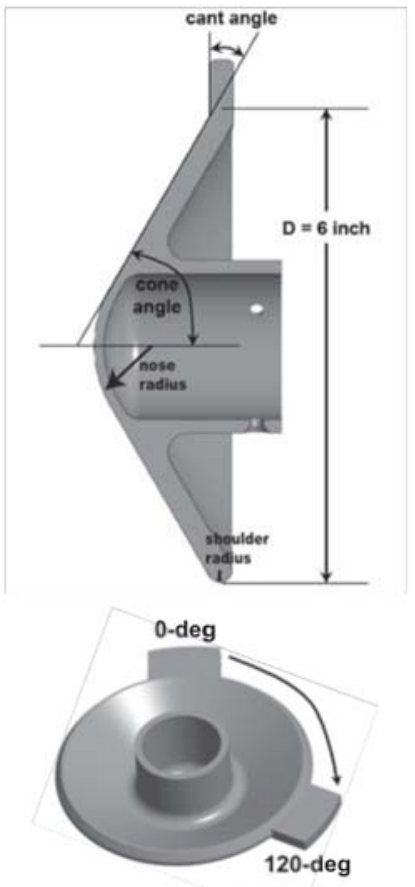

Figure 2. Trim Tab Parametric Model configuration schematic. 
Experimental aerodynamic data were obtained on 38 unique blunt body models shown in Figure 3 (One $70^{\circ}$ forebody model was already installed in the tunnel and thus only 37 models are captured in the photograph. Also shown is the MSL backshell tested on the $70^{\circ}$ forebody). Design and fabrication work was done primarily at the Langley Research Center. The models were fabricated from stainless steel with a nominal diameter of 6 inches. The model scale and material were chosen to enable testing in LaRC UPWT as well as a future entry in the Langley Aerothermodynamic Laboratory to expand the aerodynamic database to hypersonic test conditions. Tunnel occupancy costs generally outweigh fabrication expense, thus interchangeable forebodies were chosen as a preferable design to interchangeable tabs (requiring time-intensive surface filler application/removal) to maximize configurations tested for the given test budget.

Two schematics of the full model assembly are shown in Figure 4, with and without an MSL aftbody installed. The model support sting, designated LaRC 350-17B, has a 1 -inch diameter and is fabricated from Vascomax C350. The TTPM model is designed to receive a standard six-component force-and-moment balance aligned with its axis of symmetry. The primary balance used for these tests was the LaRC 2049. The balance adapter piece was fabricated from stainless steel and its outer diameter was scaled to represent a realistic aft-body for inflatable aerodynamic decelerators being studied. The interior of the balance sleeve was precision fit for the LaRC 2049 balance. The sleeve was held in place with a beryllium-

Figure 4. Trim Tab Parametric Model design schematics.

copper balance pin. Each of the forebody models could be installed/removed quickly and easily via accessible fasteners shown in the schematic without disturbing the balance sleeve/aft body. To protect the balance from freestream flow impingement, a non-metric aluminum sleeve was installed, with approximately a 1/8-inch spacing aft of metric balance adapter, for all test configurations. Although not shown in Figure 4, tubes attached to the windward and leeward pressure taps were run through passages in the balance adapter, inside the cavity created by the balance shroud, and routed through a centerline passageway in the support sting to offboard pressure transducers. Model orientation in the wind tunnel was set via a leveling block and calibrated angular measurement system (AMS) package. A pre-test installation photograph is shown in Figure 5.

\section{Facility}

The LaRC UPWT is a closed circuit, continuousrunning, pressure tunnel with two test sections that are nominally 4-ft by 4-ft in cross section and 7-ft long. The stagnation pressure can be varied up to a maximum of approximately $7000 \mathrm{psf}$ in Test Section (TS) I and approximately 14,000 psf in TS II. The nozzle throat-totest-section area ratio is varied by a lower asymmetric sliding nozzle block that provides continuous variation of the Mach number. The Mach number range is nominally 1.5 to 2.86 in Test Section I and 2.3 to 4.63 in Test Section II. Tunnel stagnation temperatures are typically

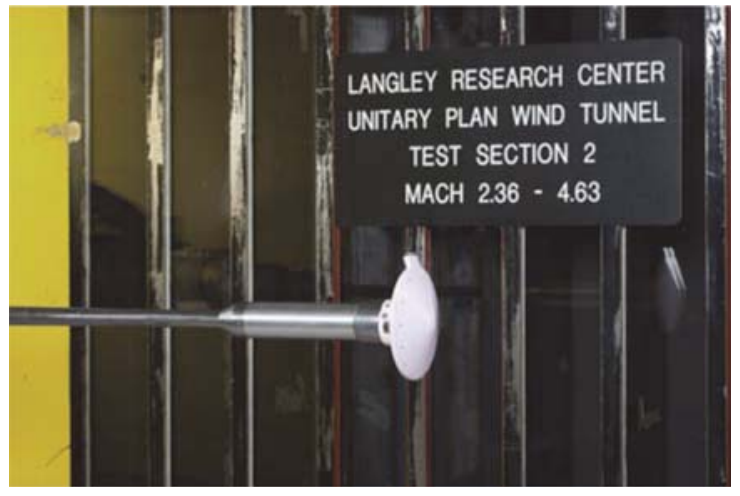

Figure 5. TTPM installed in LaRC UPWT.

Page 4 of 16 
$585^{\circ} \mathrm{R}$ and $610^{\circ} \mathrm{R}$ for each test section, respectively. Unit Reynolds numbers from 1.0 to 6.0 million per foot can be run routinely with a capability to reach 7.0 million per foot on a transient basis. Nominal flow conditions for TTPM testing are shown in Table 1. The basic model support mechanism is a horizontal wall-mounted strut that is

Table 1. Nominal flow conditions for TTPM testing in LaRC UPWT.

\begin{tabular}{lllll}
\hline $\mathbf{M}_{\infty}$ & $\mathbf{q}_{\infty}(\mathbf{p s f})$ & $\mathbf{P}_{\mathbf{T}}(\mathbf{p s f})$ & $\mathbf{T}_{\mathbf{T}}\left({ }^{\circ} \mathbf{R}\right)$ & $\mathbf{R e}_{\infty}\left(\mathbf{f t}^{-1}\right)$ \\
\hline 2.5 & 204.5 & 800 & 585 & $1.0 \times 10^{6}$ \\
3.5 & 152.6 & 1351 & 585 & $1.0 \times 10^{6}$ \\
4.5 & 113.8 & 3217 & 585 & $1.0 \times 10^{6}$ \\
\hline
\end{tabular}
capable of forward and aft travel of over 3 feet in the stream-wise direction. A main sting support attached to the strut can transverse laterally \pm 20 in and can provide a yaw capability of $\pm 12^{\circ}$. Forward of the main sting support is the angle-of-attack mechanism that provides pitch motion from $-15^{\circ}$ to $+30^{\circ}$. A roll mechanism can be installed ahead of the pitch mechanism to provide continuous roll motion over a $310^{\circ}$ range..$^{13}$

\section{Test Techniques and Instrumentation}

Given the UPWT facility capabilities described in the preceding section, several experimental techniques were used synergistically to obtain both quantitative and qualitative data on the 39 TTPM configurations to support development of the aerodynamic database.

\section{(1) Force and Moment Measurements:}

Aerodynamic forces and moments were measured using a six-component strain-gage balance, a standard experimental instrument for generating aerodynamic data. The balance used for this test program was the LaRC 2049. The majority of the force and moment data were taken in a continuous sweep mode and corrected real-time for support system deflection under loading. The continuous sweep data acquisition capability at the LaRC UPWT is a recent facility upgrade that allows for more productive tunnel operations by collecting data during the continuous movement of the model. For pitch sweeps, the model is swept through the desired angle range at a constant velocity of $1 \mathrm{deg} / \mathrm{sec}$ while data are acquired at $30 \mathrm{samples} / \mathrm{second}$. The data are then shifted in time to correct for any observed pneumatic or signal conditioning lag. Determination of pneumatic lag requires one pitchpause run per Mach and Reynolds number combination and signal conditioning lag requirements are dependent upon the equipment being used. Application of the continuous sweep capability to testing at UPWT has allowed for test programs to be run in half the wind-on time that would have been required to run the same matrix using the traditional pitch-pause mode. Flow angularity is typically measured for each test entry using $\mathrm{dC}_{\mathrm{N}} / \mathrm{d} \alpha$ values for upright and inverted runs at angles of attack near zero. Because these values are small for a blunt body (dominated by axial force at low angles of attack) these data would not provide sufficient resolution to characterize flow angularity. Thus, data were corrected post-test for flow angularity based on existing facility calibrations. The angularity is a function of tunnel freestream flow conditions (predominantly Mach number) and location in the test section. Two static pressures were measured in the base area using an off-board electronically scanned pressure (ESP) module, but no corrections were made to the data. Base pressures are small for this model with no sting cavity, so traditional base and cavity corrections would cancel each other. Wind-off balance readings were monitored before and after each run, and balance components were monitored during the tunnel run for drift caused by thermal gradients across the balance gages. Hysteresis checks were done by comparing ascending and descending pitch sweep data, and within-test repeatability was checked by repeating selected runs in the test matrix. Observed variations were compared to quoted balance accuracies for all six components based on the $\pm 95 \%$

Table 2. Balance loads and component accuracies for the LaRC 2049 balance.

\begin{tabular}{|c|c|c|c|c|c|c|c|}
\hline & & NF(lbf) & AF(lbf) & PM(in-lbf) & RM(in-lbf) & YM(in-lbf) & SF(lbf) \\
\hline \multicolumn{2}{|c|}{ Movimum I } & 100 & 225 & 150 & 50 & 120 & 60 \\
\hline \multicolumn{2}{|c|}{ Accuracy (\%F.S.) } & 0.15 & 0.09 & 0.16 & 0.11 & 0.11 & 0.14 \\
\hline \multicolumn{2}{|c|}{ Accuracy (Load) } & 0.150 & 0.203 & 0.240 & 0.055 & 0.132 & 0.084 \\
\hline $\mathbf{M}_{\infty}$ & $\mathbf{q}_{\infty}(\mathbf{p s f})$ & $C_{N} \pm 2 \sigma$ & $C_{A} \pm 2 \sigma$ & $C_{m} \pm 2 \sigma$ & $C_{1} \pm 2 \sigma$ & $C_{n} \pm 2 \sigma$ & $C_{Y} \pm 2 \sigma$ \\
\hline 2.5 & 204.5 & \pm 0.0037 & \pm 0.0050 & \pm 0.0010 & \pm 0.0002 & \pm 0.0005 & \pm 0.0021 \\
\hline 3.5 & 152.6 & \pm 0.0050 & \pm 0.0068 & \pm 0.0013 & \pm 0.0003 & \pm 0.0007 & \pm 0.0028 \\
\hline 4.5 & 113.8 & \pm 0.0067 & \pm 0.0090 & \pm 0.0018 & \pm 0.0004 & \pm 0.0010 & \pm 0.0038 \\
\hline
\end{tabular}


confidence level from balance calibration reports. Balance loads and $\pm 2 \sigma$ accuracies for representative flow conditions are also shown in Table 2 . It should be noted that the aforementioned balance accuracies represent only the uncertainties associated with the balance itself. This would be a measure of the overall uncertainty on the wind tunnel measurements only in the absence of all other variations. Aerodynamic data obtained from differently scaled models in multiple wind tunnel facilities will be statistically analyzed to obtain the most rigorous estimate of overall uncertainty for input into an aerodynamic database.

\section{(2) Virtual Diagnostics Interface (ViDI)}

The Virtual Diagnostics Interface ${ }^{14}$ is comprised of a series of inter-related tools that are used by researchers to facilitate pre-test planning as well as real-time and post-test data visualization. The common thread throughout the ViDI applications is the use of an interactive, three-dimensional virtual environment containing accurately scaled representations of the experimental facility and test articles. For the TTPM test program in LaRC UPWT, use of ViDI simulation capabilities enabled efficient determination of the feasibility of optical-based experimental tools and facilitated optimized installation of test articles for synergistic use of test techniques.

One of the key aspects of ViDI is its pre-test simulation capability, enabling an experiment to be executed first in a virtual environment. Figure 6 depicts an optical simulation of the TTPM model installed in the UPWT. To obtain PSP images of the model, a mirror was attached to the side of one of the large slats on the side of the wind tunnel test section door. The image was simulated by creating ray-traced renderings of the reflections off of a virtual mirror modeled in the scene. A variety of camera angles and mirror placements were simulated until an optimum solution was determined. The pre-test simulation verified that the existing mirror provided adequate view angles of the model throughout the range of angles of attack to be tested.

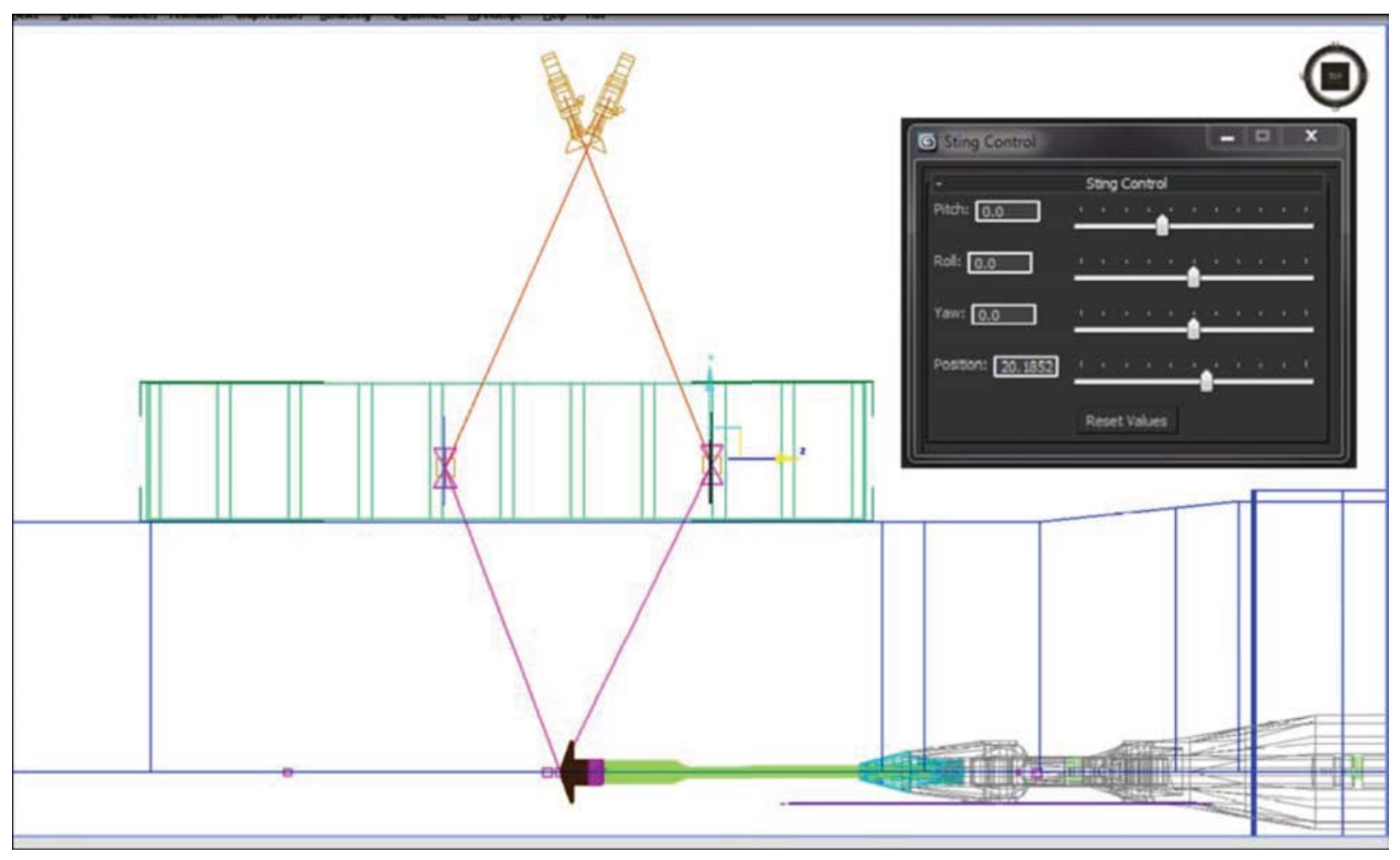

Figure 6. ViDI simulation of TTPM in LaRC UPWT.

\section{(3) Pressure Sensitive Paint (PSP)}

Pressure sensitive paint allows non-intrusive global surface pressure measurements to be made using an optical detector (camera). Two primary advantages of PSP are: 1) it provides a more complete pressure distribution than is possible with individual pressure orifices, and 2) it permits the acquisition of data in areas inaccessible to conventional pressure measurements. A model surface is coated, typically via spray application, with PSP that is 
made up of a luminescent probe molecule held in an oxygen permeable binder. The probe molecule is chosen such that its luminescence is quenched by oxygen. When the model is being tested in the wind tunnel (Figure 7), ultraviolet light from a high intensity LED lamp is pulsed onto the surface, and the molecules fluoresce in a visible light wavelength. The intensity of the visible light is inversely proportional to the amount of oxygen above the coating. Higher pressures cause more oxygen molecules to permeate the binder in the paint, resulting in less fluorescence. This change of intensity can be converted to a quantitative change in pressure via an appropriate calibration. Ratios of wind-off and wind-on images are used

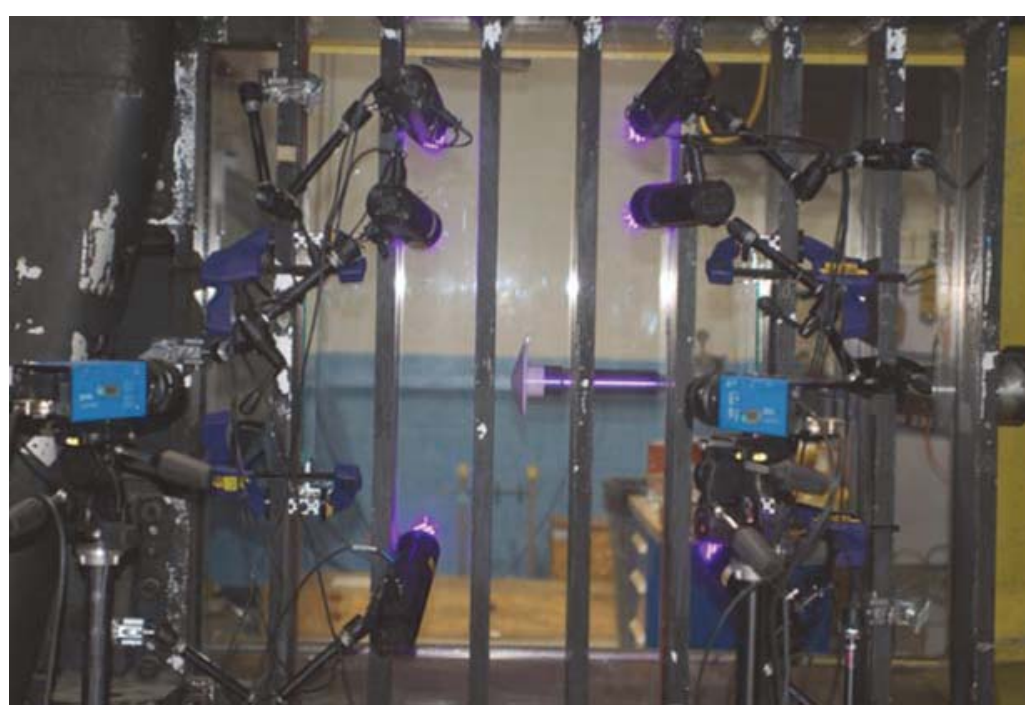

Figure 7. PSP Apparatus for TTPM testing in LaRC UPWT. to remove effects of variation of paint thickness, particle distribution, and illumination. Resulting pressure distributions are adjusted for bias error, primarily expected from temperature effects, by measured static pressures on the model. More detailed information on PSP techniques can be found in Reference 15.

\section{(4) Static Pressure Measurements:}

To anchor PSP pressure distributions, limited surface pressure measurements were made using a commercially available ESP module. The module used for this study was rated for a nominal maximum pressure of 15 psid to capture the range of higher pressures expected on the windward heat shield and the lower pressures expected on the cylindrical aft-body. The differential ESP module was used as an absolute gage by evacuating the reference side of the modules using a common vacuum source. Given the scale of the model, the ESP module could not be mounted internally to the model and thus was located aft of the tunnel support strut just outside the test section to minimize tubing length and corresponding settling times. Pressure tubing leading from surface orifices had an inside-tooutside diameter ratio (I.D./O.D.) of $0.020 \mathrm{in./0.040} \mathrm{in.} \mathrm{and} \mathrm{exited} \mathrm{the} \mathrm{model} \mathrm{directly} \mathrm{through} \mathrm{the} \mathrm{1-inch} \mathrm{diameter}$ sting and out the back of the sting coupling in a protective casing with a total length of approximately 10 feet.

Static pressure data were taken after allowing the model to sit at each angle of attack for 10-15 seconds as required by PSP data collection. (Pressure settling times were verified by generating unchanged results with across model dwell.) Pressure readings were collected at 30 samples per second over a 2-second interval and averaged to yield each data point. Pressure data repeated within the manufacturer-specified uncertainty of $\pm 0.1 \%$ of full-scale module pressure rating.

\section{(5) Schlieren Flow Field Visualization:}

Standard schlieren systems use light from a single collimated source focused through a lens on a knife-edge to visualize density variations in the flow field around a test article. Corresponding variations in refractive index caused by density gradients in the fluid distort the collimated light. The result is a set of lighter and darker regions corresponding to positive and negative fluid density gradients in the direction normal to the knife-edge. Thus, salient flow field features such as shock waves and flow separation/reattachment can be visualized. Figure 8 shows a schlieren image of a tab configuration at a nonzero angle of attack.

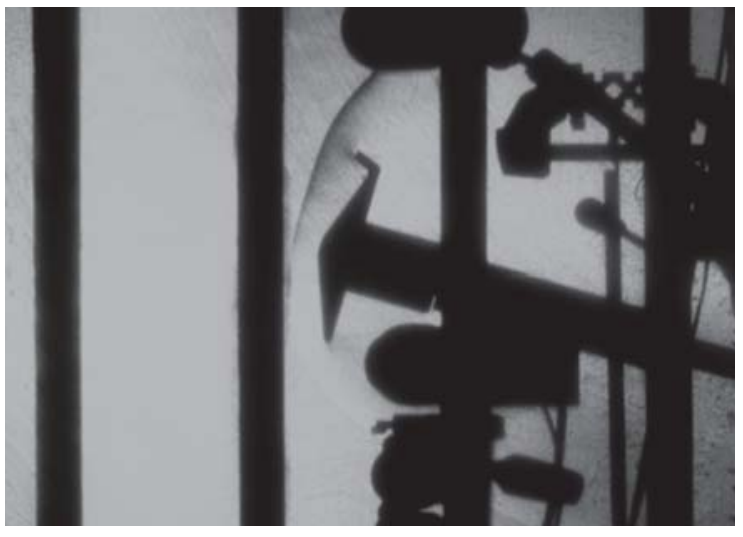

Figure 8 - TTPM Schlieren in LaRC UPWT. 


\section{Test Plan}

The ranges of all attitude, flow field, and configuration parameters for Test 1875 are listed below:

\section{Attitude Parameters}

- Angles of attack: $-4^{\circ}$ to $+20^{\circ}$.

- Angle of sideslip: $-8^{\circ}$ to $+8^{\circ}$

- Angle of roll: $0^{\circ}$ for all runs.

Flow Field Parameters

- Mach numbers: 2.5, 3.5, 4.5

\section{Configuration Parameters}

- Forebody: $50^{\circ}$ sphere-cone, $60^{\circ}$ sphere-cone, $70^{\circ}$ sphere-cone, Apollo

- Aftbody: Cylindrical, MSL

- Tab quantities: $0,1,2$

- Tab locations: $0^{\circ}, 90^{\circ}, 120^{\circ}, 180^{\circ}$

- Tab areas: $1.5 \%, 3 \%, 6 \%$

- Tab aspect ratios: 1:1, 1:2, 2:1

- Tab cant angles: 0 to $90^{\circ}$

Table 3 show a listing of specific configuration parameters tested, detailing the relative magnitude of runs devoted to each forebody shape. Despite the improved efficiency with continuous sweep data and extremely efficient model change procedures, the four-week tunnel occupancy would not afford testing all possible combinations of the above variables, and thus the test matrix is non-square with regard to possible tab parameters. Tab area and tab aspect ratio effects cannot be fully decoupled, as the moment arm of the tab changes with each of these parameters. Additionally, variation across the full range of tab cant angles $\left(0^{\circ}\right.$ to $\left.90^{\circ}\right)$ is only available for the $3 \%$ area tabs with a 2:1 tab aspect ratio. However, a minimum of two variations in each tab parameter and the no-tab baseline are available for each forebody geometry and Mach number condition. Figures 9-11 shows examples of the different forebody geometries, tab areas, tab aspect ratios and tab cant angles to illustrate how parametric effects were drawn from the above matrix.

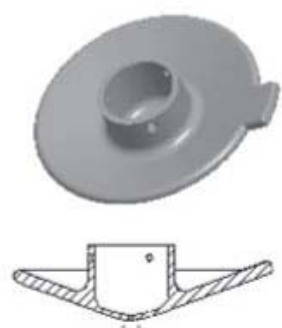

70 deg S-C
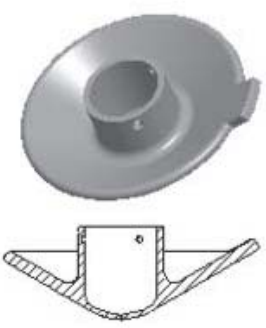

60 deg S-C
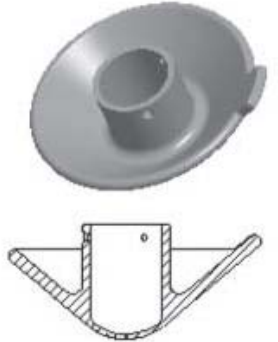

50 deg S-C

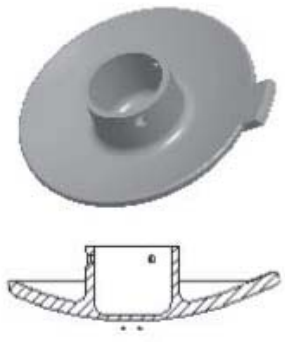

Apollo

Figure 9. TTPM forebody parametric, $3 \%$ tab area and $0^{\circ}$ tab cant angle. 

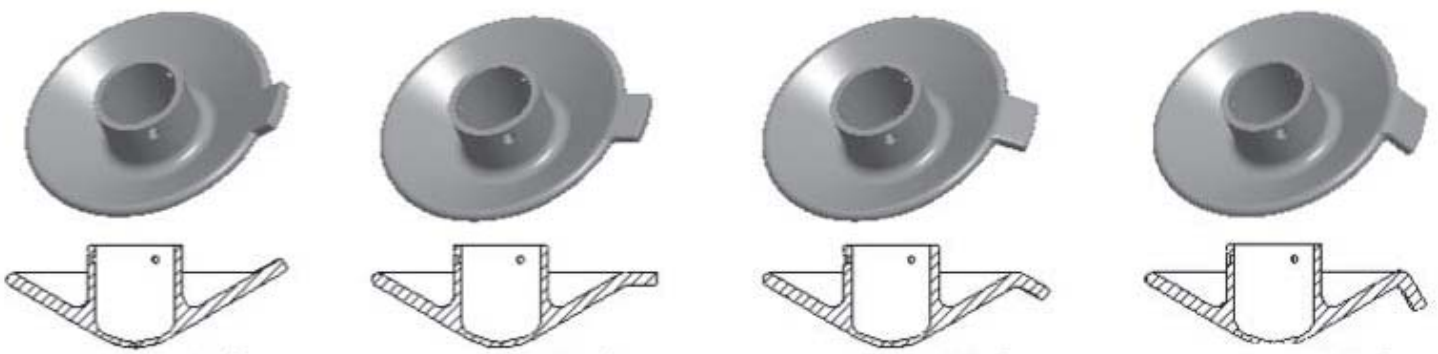

0 deg

30 deg

60 deg

90 deg

Figure 10. TTPM tab cant angle parametric, 60-degree forebody with $3 \%$ tab area.

3\%-scale

$A R=2: 1$
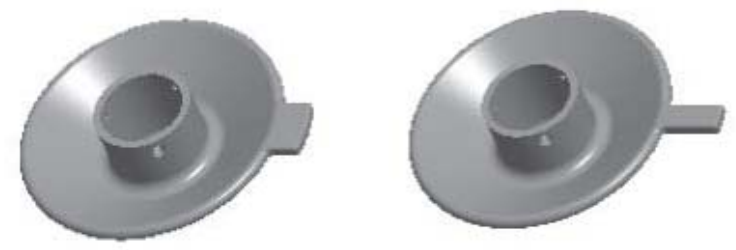

3\%-scale

$A R=1: 2$
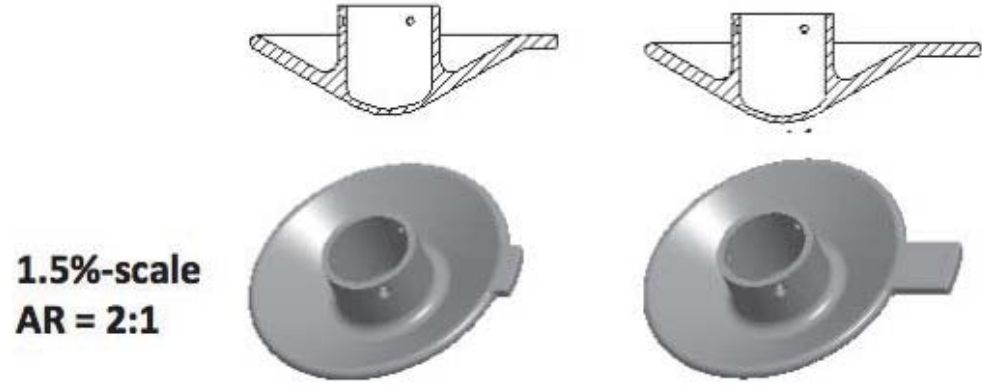

6\%-scale

$A R=1: 1$
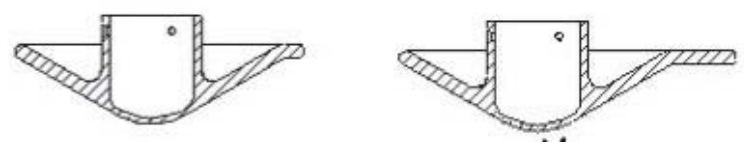

Figure 11. TTPM coupled tab area and tab aspect ratio parametric.

\section{Results}

\section{Aerodynamic Data}

Aerodynamic data were obtained for the TTPM configuration based on the coordinate reference system shown in Figure 12. All data are presented in coefficient form using appropriately scaled reference dimensions for a 6-

Table 4. TTPM

\section{Reference dimensions}

\begin{tabular}{ll}
\hline Lref (in) & 6 \\
\hline Sref (in $\left.{ }^{2}\right)$ & 28.27 \\
Xmrc (in) & 0 \\
\hline Ymrc (in) & 0 \\
Zmrc (in) & 0 \\
\hline
\end{tabular}

inch diameter model with moment reference center (mrc) about the configuration "nose," i.e. the center point of the blunt sphere-cone geometry. Configuration reference dimensions are shown in Table 4. The reader is referred to the work of Korzun, et al., ${ }^{16}$ for an extensive analysis of trim characteristics and resulting vehicle design implications for these trim tab data at realistic centers of gravity.

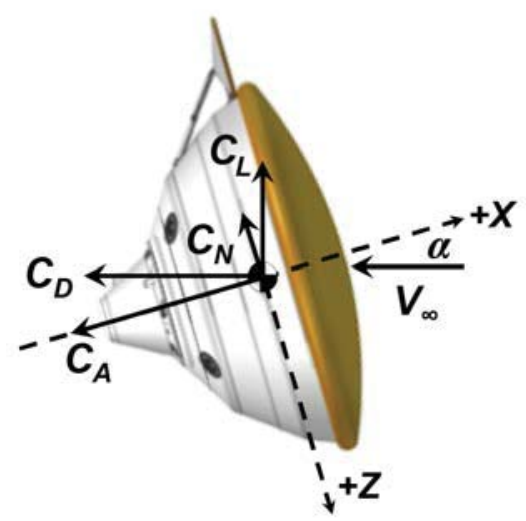

Figure 12. TTPM aerodynamic coordinate system. 


\section{Continuous Sweep Data}

Figure 13 shows a representative comparison of longitudinal aerodynamic data taken in both continuous pitch and pitch-pause modes. Data shown are for the 70-degree forebody with a single tab (3\% area, 2:1 aspect ratio, $0^{\circ}$ cant angle) at $\mathrm{M}_{\infty}=4.5$. Continuous sweep data allowed curve fits for aerodynamic trends to be generated from more than 130 points over the angle of attack range tested. The small red points on the curves in Figure 13 are the continuous sweep data, the large blue points are data from pitch-pause test runs, and the solid black line is a curve fit generated from all of the data obtained. Quadratic least-square curve fits (least squares approach) were developed for $C_{A}, C_{N}, C_{D}, C_{L}, C_{m, r e f}$, and $L / D$ as a function of $\alpha$ for each configuration and Mach number for initial analysis of this data set. ${ }^{15}$ Calculation of the $\mathrm{R}^{2}$ value for each fit from the sum squared error and the total sum of squares yields a minimum $\mathrm{R}^{2}$ value of 0.96 across all cases, with $\mathrm{R}^{2}$ exceeding 0.99 for the majority of the fits. The dashed black lines represent the $\pm 2 \sigma$ balance accuracy on the wind tunnel test data. These accuracies were shown previously in Table 2 and are applicable in Figure 13 to $\mathrm{C}_{\mathrm{A}}, \mathrm{C}_{\mathrm{N}}$, and $\mathrm{C}_{\mathrm{m} \text {,ref. }}$.
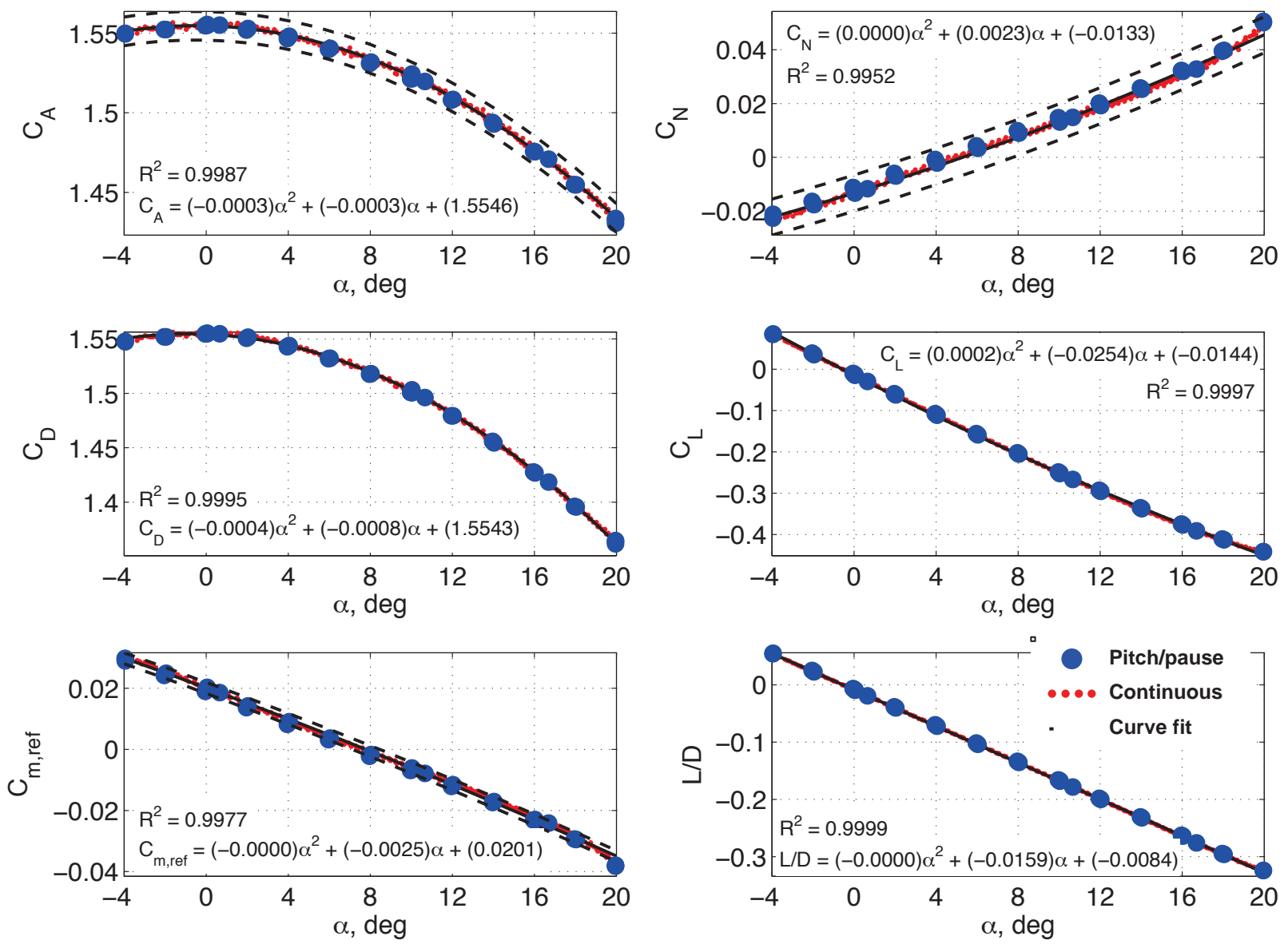

Figure 13. Comparison of continuous and pitch-pause data collection for 70-degree forebody at $M_{\infty}=4.5$.

\section{Comparison with Historical Data}

Figure 14 shows a comparison of the no-tab baseline 70-degree forebody data from T1875 with other 70deg sphere-cone historical data sets as an initial check on the most recent test data. These data sets are: LaRC UPWT Test 1735 - Mars Smart Lander aerodynamic testing, ${ }^{10}$ Viking aerodynamic testing, ${ }^{17}$ and MSL aerodynamic testing. ${ }^{18}$ Conditions vary across these tests, namely $\mathrm{Re}_{\infty}, \mathrm{M}_{\infty}$, $\alpha$, and the configuration of the backshell (no backshell, flat face, biconic, and MSL, respectively). Data from all of the tests in Figure 14 show higher order behavior in $C_{A}$ at lower Mach numbers (below Mach 2.7) and more quadratic behavior at higher Mach numbers (above Mach 2.7). The $\mathrm{C}_{\mathrm{N}}$ data for cases with a backshell (T1735 and MSL) exhibit non-monotonically increasing behavior with increasing angle of attack between $\alpha=-5^{\circ}$ and $+5^{\circ}$ at Mach numbers of 2.5 and below. 
This behavior is not seen under any conditions in the $\mathrm{C}_{\mathrm{N}}$ data from $\mathrm{T} 1875$ and the Viking test, both of which used a balance shroud and no backshell. The overall trends in $\mathrm{C}_{\mathrm{A}}$ and $\mathrm{C}_{\mathrm{N}}$ for the T1875 baseline configuration agree well with data from other tests for the same forebody.
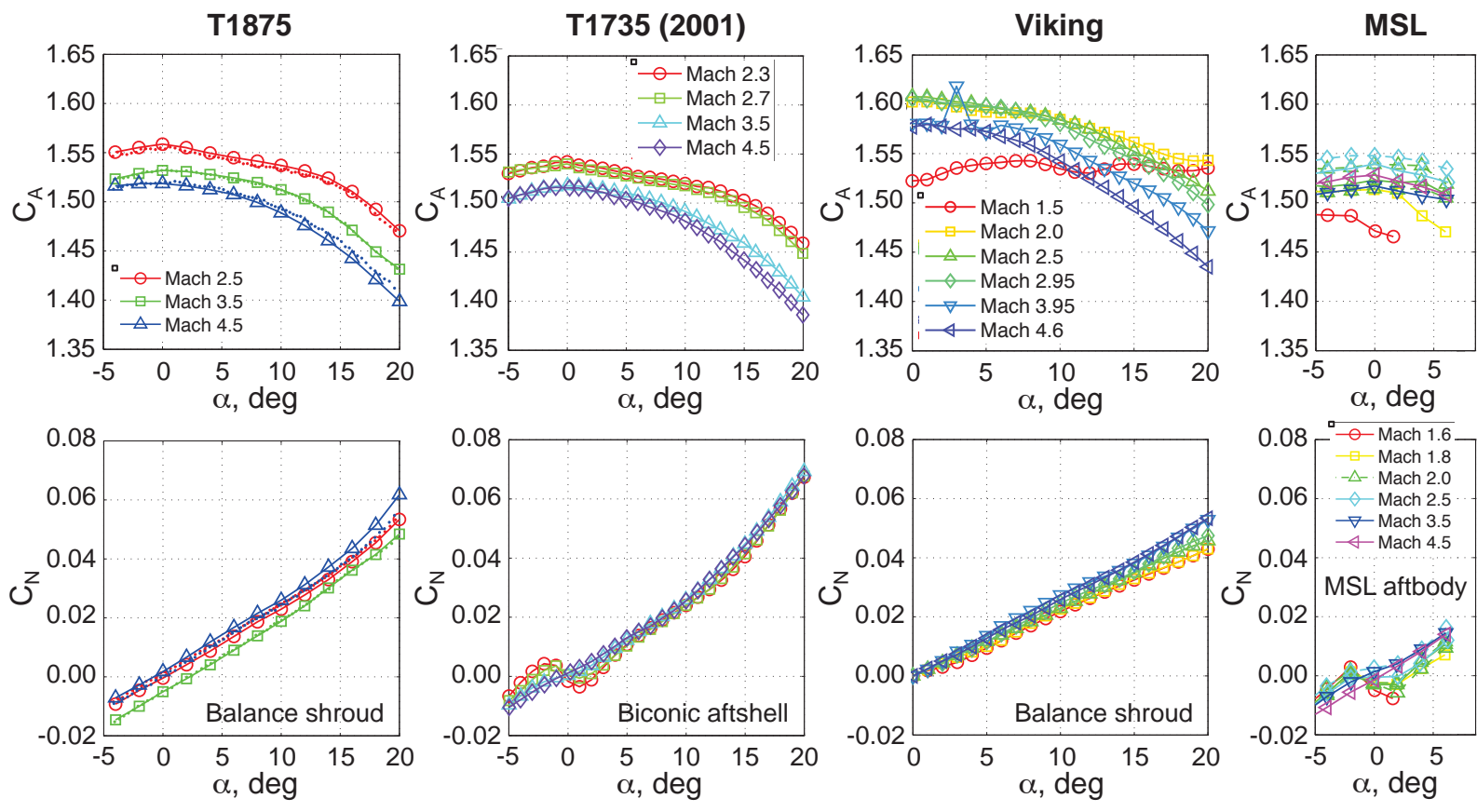

$\operatorname{Re}_{\infty} / \mathrm{ft}=1 \times 10^{6}$

$\operatorname{Re}_{\infty} / \mathrm{ft}=2 \times 10^{6}$

$\operatorname{Re}_{\infty} / \mathrm{ft}=1 \times 10^{6}$

$\operatorname{Re}_{\infty}=1,2,3 \times 10^{6}$

Figure 14. Comparison of TTPM data from LaRC UPWT Test 1875 with historical 70-degree forebody data.

\section{Configuration Parametrics}

Trends in aerodynamic coefficient data $\left(\mathrm{C}_{\mathrm{A}}, \mathrm{C}_{\mathrm{N}}, \mathrm{C}_{\mathrm{D}}, \mathrm{C}_{\mathrm{L}}, \mathrm{C}_{\mathrm{L}}, \mathrm{C}_{\mathrm{m}, \mathrm{ref}}, \mathrm{C}_{\mathrm{n}}, \mathrm{L} / \mathrm{D}\right)$ with angles of attack and sideslip are explored for different forebody geometries, different numbers of tabs, and different tab parameters in Figures 15-17. All moment coefficients are referenced to the model nose and data presented are interpolated curves from individual wind tunnel runs (only selected points shown in some cases to facilitate viewing).

Figure 15 shows the effect of varying forebody geometry on longitudinal aerodynamic coefficients as a function of angle of attack at $\mathrm{M}_{\infty}=4.5$. The 50-degree forebody exhibits the most extreme aerodynamic characteristics of the group of configurations, with lower drag, higher longitudinal stability, and lower L/D with increasing angle of attack (non-linear changes with forebody angle are expected from basic Newtonian theory).

The parameter of greatest interest for two-tab configurations was yawing moment, and Figures 16(a) and 16(b) show $C_{n}$ as a function of sideslip angle for the configurations tested with 0,1 , and 2 tabs for both the 70degree and 60-degree forebodies. The asymmetric tab configurations show significant yawing moment increments for all angles of sideslip.

Figures 17(a) and 17(b) show the longitudinal aerodynamic coefficient trends for all of the single-tab configurations and the no-tab baseline configuration for the 70-degree forebody at $\mathrm{M}_{\infty}=4.5$, grouped by tab area. As expected, the addition of a trim tab generates a positive pitching moment increment, as compared to the no-tab baseline. The largest shift in $\mathrm{C}_{\mathrm{m}, \mathrm{ref}}$ occurs for the tabs with the greatest area (6\%, relative to the base area). Increasing the tab cant angle from parallel to the forebody $\left(0^{\circ}\right)$ to perpendicular to the body axis $\left(20^{\circ}\right.$ cant angle for the 70-degree forebody) also increases $\mathrm{C}_{\mathrm{m}, \mathrm{ref}}$ across angles of attack from $-4^{\circ}$ to $+20^{\circ}$.

Of the three tab parameters, changing the tab aspect ratio has the smallest effect. With the exception of the $90^{\circ}$ canted tab, varying the trim tab geometry shifts the magnitude of force and moment coefficients with minimal change to the shape of the overall trends with angle of attack. In contrast, the $90^{\circ}$ canted tab imparts a normal force contribution that is significantly greater than that of the other trim tabs, resulting in slope variations of force-andmoment coefficients with angle of attack that are, in general, smaller than those for the trim tab configurations with smaller tab cant angles. 

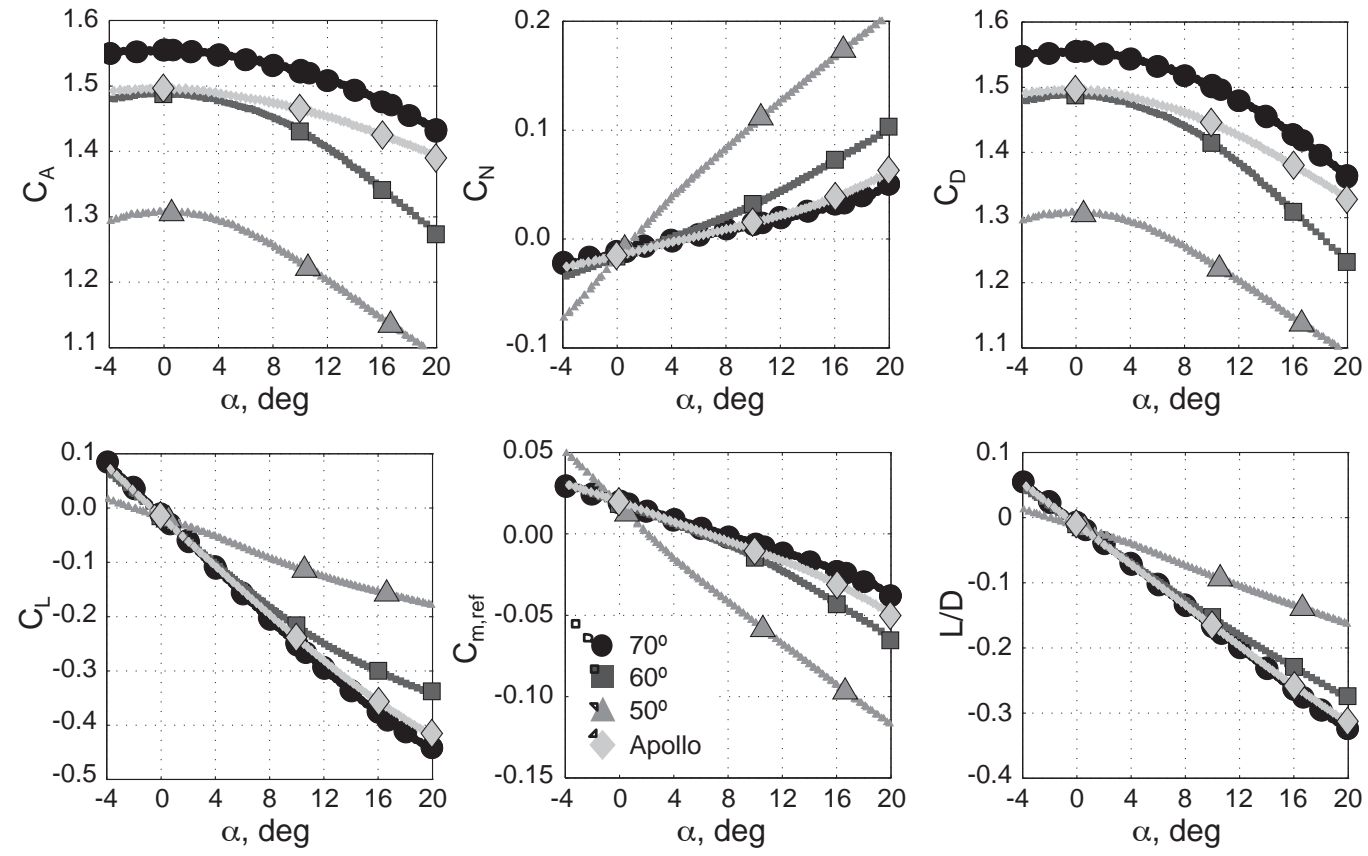

Figure 15. Effect of forebody shape for single tab (3\% area, $2: 1$ aspect ratio, $0^{\circ}$ cant angle) at $\mathbf{M}_{\infty}=4.5$.
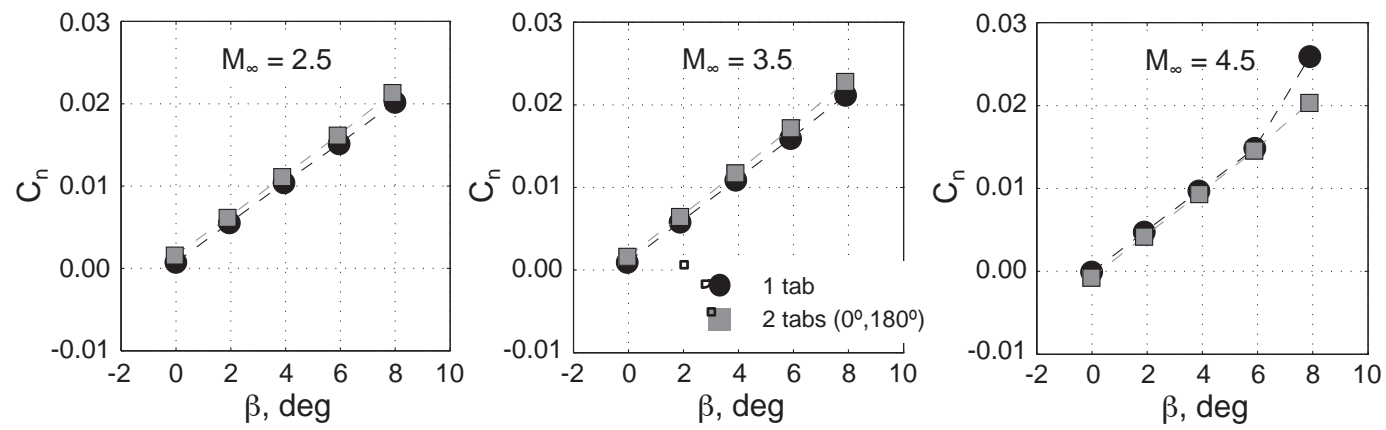

(a) $70^{\circ}$ forebody, $\alpha=16^{\circ}, \operatorname{tab}(\mathrm{s})$ : $3 \%$ area, $2: 1$ aspect ratio, $20^{\circ}$ tab cant angle
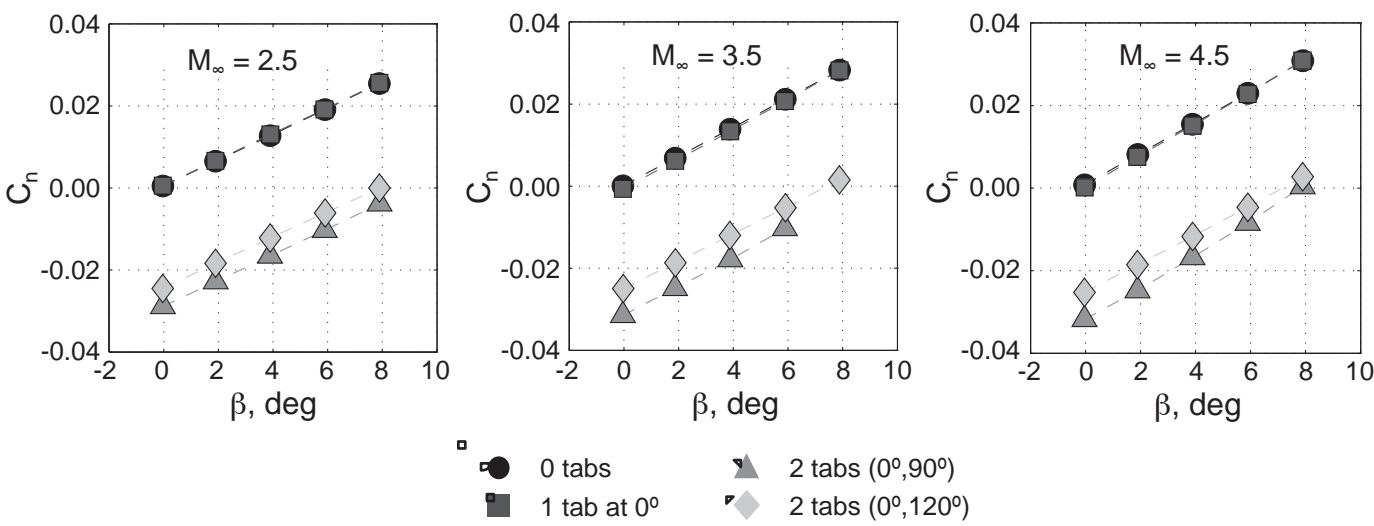

(b) $60^{\circ}$ forebody, $\alpha=16^{\circ}$, tab(s): $3 \%$ area, $2: 1$ aspect ratio, $30^{\circ}$ tab cant angle

Figure 16. Effect of tabs on TTPM yawing moment coefficient. 

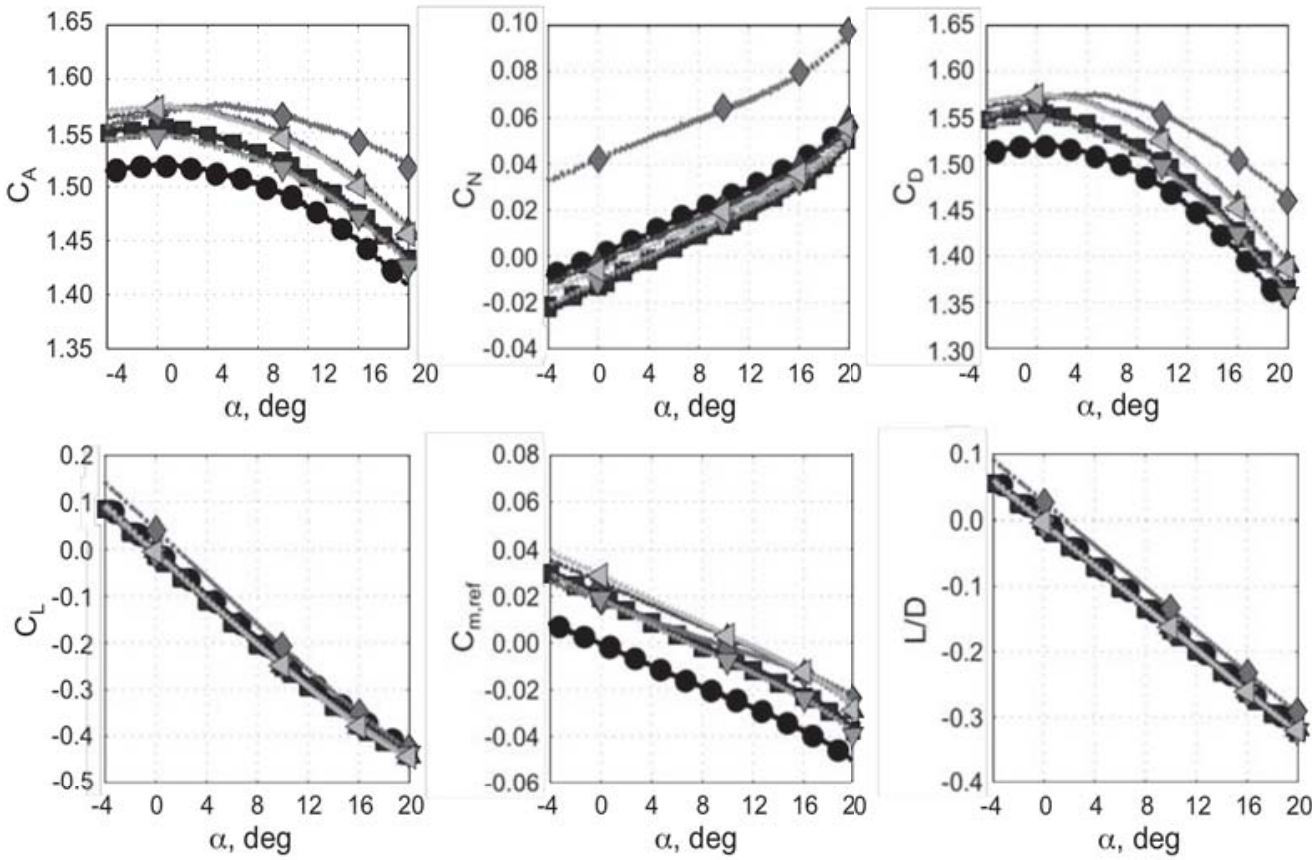

\begin{tabular}{|ll|}
\hline 0 Tabs & $\searrow 3 \%(2: 1) 90^{\circ}$ \\
$3 \%(2: 1) 0^{\circ}$ & $\nabla 3 \%(1: 2) 0^{\circ}$ \\
$3 \%(2: 1) 20^{\circ}$ & $\triangleleft 3 \%(1: 2) 20^{\circ}$ \\
\hline
\end{tabular}

Figure 17 (a). Effect of tab cant angle and tab aspect ratio on TTPM longitudinal aerodynamic coefficients for the 70degree forebody with a $3 \%$ area tab at $M_{\infty}=4.5$.
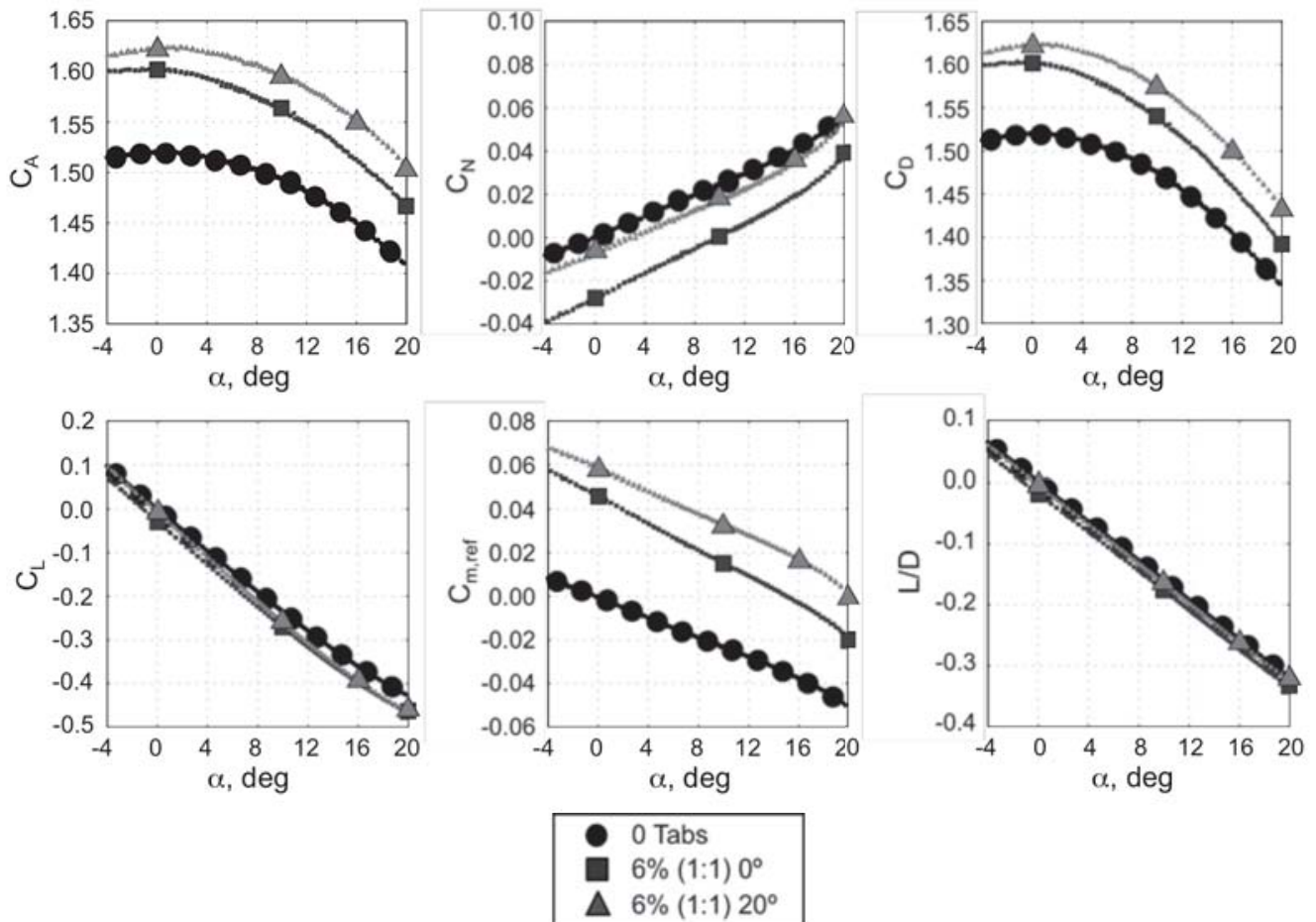

Figure 17 (b). Effect of tab cant angle on TTPM longitudinal aerodynamic coefficients for the 70-degree forebody with a $6 \%$ area tab at $M_{\infty}=4.5$. 


\section{Pressure Data}

PSP techniques were used to generate global surface pressure distribution on 19 of the 39 aerodynamic models tested in Test 1875 . The majority of PSP data were obtained for the 70-degree and 60-degree forebody configurations, with very limited data taken for the 50-degree and Apollo configurations. ViDI simulation capabilities were used to facilitate PSP installation and data collection. To anchor the PSP results, representative discrete surface pressure data were generated on each forebody shape via single static pressure orifices on both the
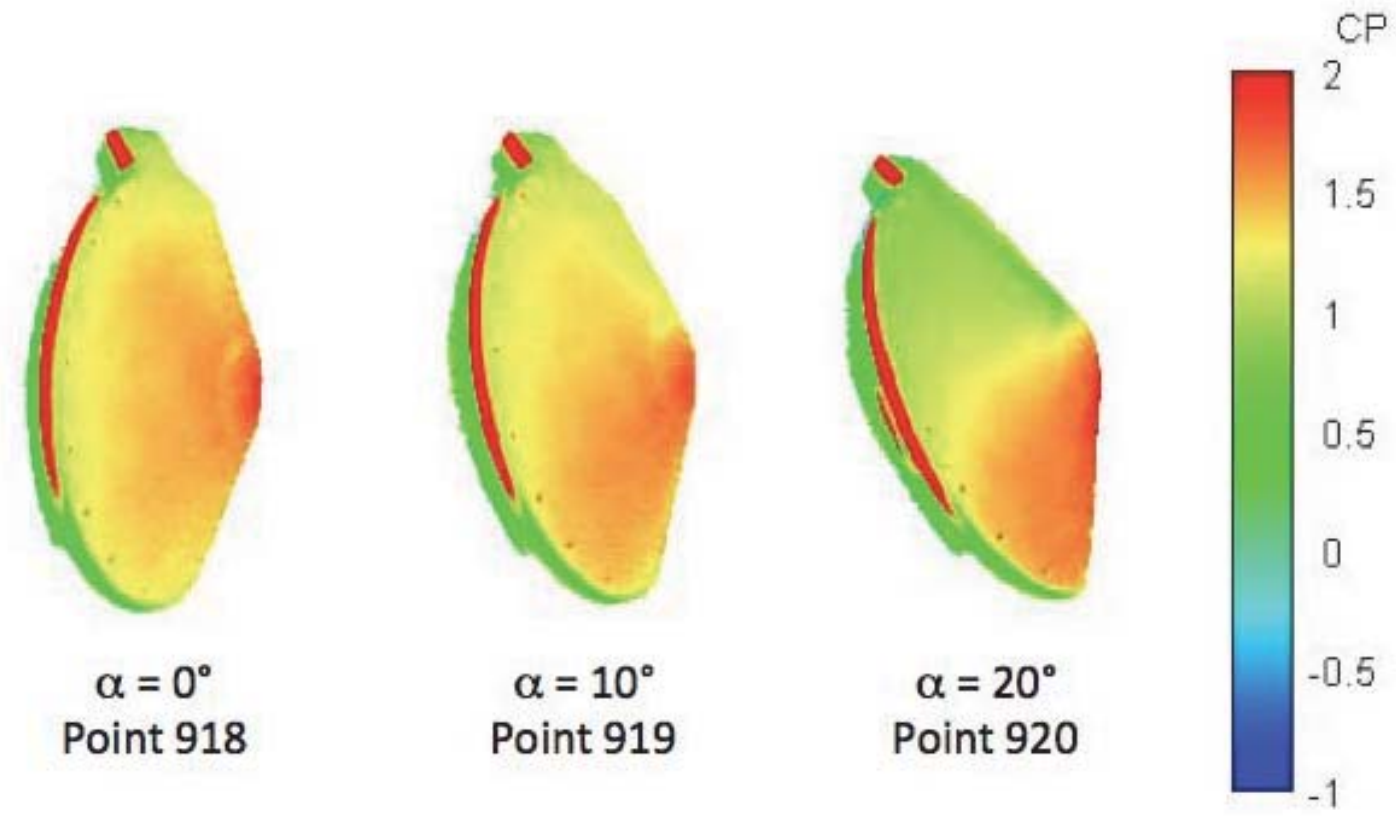

Figure 18(a). PSP Images of the TTPM with a 60-degree forebody and $0^{\circ}$ canted tab at $M_{\infty}=4.5$

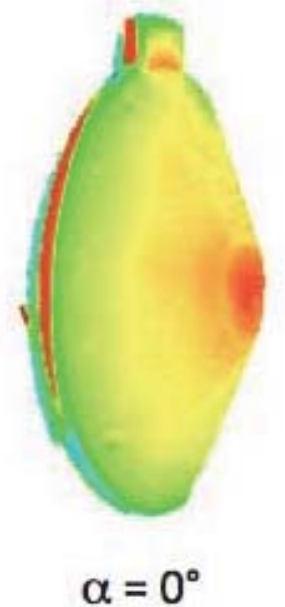

Point 866

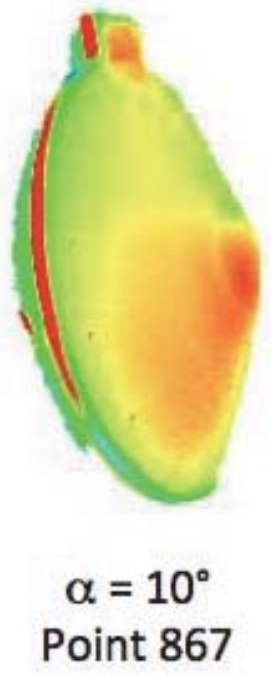

Point 868

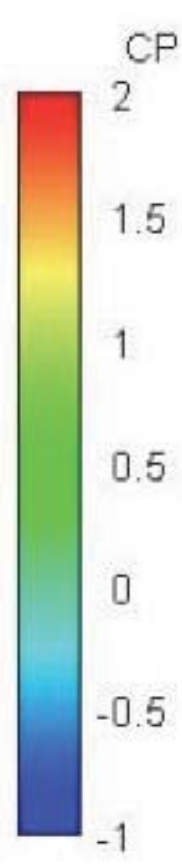

Figure 18(b). PSP Images of the TTPM with a 60-degree forebody and $30^{\circ}$ canted tab at $M_{\infty}=4.5$ 
windward and leeward sides of the model. These global pressure distributions will be used in a qualitative sense to enhance understanding of the comparison of experimental results with CFD solutions.

Figures 18(a) and 18(b) show sample PSP images generated in the test program on the 60-degree forebody at Mach 4.5 for angles of attack $0^{\circ}, 10^{\circ}$, and $20^{\circ}$. These images are produced from integration of information from multiple cameras with $\mathrm{C}_{\mathrm{p}}$ values calculated based on system calibration followed by a bias adjustment to measured surface static pressures for corresponding conditions. The color distribution on the forebody images is explained with the spectrum key to the right of the images in both figures with some caveats. In Figure 18(a) flow stagnation regions can be seen in red (highest $C_{p}$ values), moving off the forebody nose as angle of attack is increased. Decreasing pressures are seen on the $0^{\circ}$ tab with increasing angle of attack as the tab and corresponding area of the forebody is seeing flow at a more oblique angle. Areas of solid red aft of the heat shield shoulder indicate saturated portions of the image (rather than true high pressure regions) resulting from reflections and/or scaling compromises to obtain images of better resolution in areas of interest. Figure 18(b) is a corresponding set of PSP images for the same forebody, angles of attack, and Mach number, but with the tab now canted to $30^{\circ}$. For these conditions PSP shows the highest pressures on the tab at $\alpha=10^{\circ}$ (rather than $\alpha=0^{\circ}$ as seen in for the $0^{\circ}$ cant angle in the upper set of images). This type of qualitative information will prove extremely useful in understanding how and where localized effects can be significant to the integrated aerodynamic data.

\section{Conclusions}

In support of supersonic aerodynamic database development for trim tabs, testing was conducted in Test Section 2 of the NASA Langley Unitary Plan Wind Tunnel on sub-scale force-and-moment models with multiple forebody shapes and trim tab geometries. A more significant up-front design and fabrication burden was undertaken in generating 38 unique forebody models, rather than interchangeable tabs as used in previous studies, to maximize the volume of data acquired for the allotted tunnel occupancy time. The test program greatly benefited from the recently-implemented continuous sweep data reduction capability, and the largest experimental trim tab database to-date was collected. A suite of other experimental tools was used to complement traditional integrated force-and-moment testing. Pressure sensitive paint (PSP) techniques were used to generate low-fidelity global surface pressure distributions on a subset of the force and moment models. Virtual Diagnostic Interface (ViDI) simulation capabilities were used to facilitate PSP installation and data collection, and discrete surface pressure data were obtained to anchor the PSP results. These global pressure distributions will be used to enhance understanding of the comparison of experimental results with future CFD solutions. Although test parameters were sometimes coupled due to tunnel occupancy constraints (i.e. the matrix was non-square due to the large number of configuration variables), useful comparisons could be made for the configuration parameters of forebody shape, tab area, tab cant angle, and tab aspect ratio. Over the range of parameters tested, the effects of varying tab area and tab cant angle were found to be much more significant than varying tab aspect ratio relative to key aerodynamic performance requirements. This experimental database will allow for a detailed analysis of tab performance characteristics and also the resulting design implications for planetary entry configurations and their EDL performance.

\section{References}

${ }^{1}$ NASA Entry, Descent, and Landing Roadmap, Technology Area 09, November 2010.

2 Ivanov, Mark C., et al, "Entry, Descent and Landing Systems Analysis Study: Phase 2 Report on Mars Science Laboratory Improvement," NASA TM 216988, January 2011.

${ }^{3}$ Sammonds, R. I. and Dickey, R. R., "Effectiveness of Several Control Arrangements on a Mercury-Type Capsule,” NASA TM X-579, October 1961.

${ }^{4}$ Tendeland, T. and B.D. Pearson, J., "Effectiveness of Two Flap Controls on a Mercury Type Capsule at a Mach Number of 15 in the Ames Hypersonic Helium Tunnel," NASA TM X-660, November 1962.

${ }^{5} \mathrm{~N}$

5 Neal, L., Jr., "An Exploratory Investigation at a Mach Number of 6.9 into the Use of Aerodynamic

Controls for Modulating the Lift-Drag Ratio of an Apollo Type Configuration," NASA TM X-816, May 1963.

${ }^{6}$ Lockwood, M. K., Sutton, K., Prabhu, R. K., Powell, R. W., Graves, C. A., Epp, C. D., and Carman, G. L., "Entry Configurations and Performance Comparisons for the Mars Smart Lander," AIAA Paper 2002-4407, August 2002. 
${ }^{7}$ Zang, T. A., Cianciolo, A. M., Ivanov, M. C., Sostaric, R. R., and Kinney, D. J., "Overview of the NASA Entry, Descent and Landing Systems Analysis Studies for Large Robotic-class Missions," AIAA Paper, 20117294, September 2011.

${ }^{8}$ Winski, R. G., Garcia-Llama, E., Prakash, R., Shidner, J. D., Grover, M. R., and Ivanov, M. C., "Entry, Descent, and Landing Performance Trades to Increase Landed Mass for the Mars 2018 Mission," IEEEAC Paper 1236, March 2012.

${ }^{9}$ Horvath, T. J., O’Connell, T. F., Cheatwood, F. M., Alter, S. J., and Prabhu, R. K., "Experimental Hypersonic Aerodynamic Characteristics of the 2001 Mars Surveyor Precision Lander with Flap," AIAA Paper 2002-4408, August 2002.

${ }^{10}$ Murphy, K. J., Horvath, T. J., Erickson, G. E., and Green, J. M., "Supersonic Aerodynamic Characteristics of Proposed Mars '07 Smart Lander Configurations," AIAA Paper 2002-4409, August 2002.

${ }^{11}$ Edquist, K. T., Liechty, D. S., Hollis, B. R., and Alter, S. J., "Aeroheating Environments for a Mars Smart Lander," AIAA Paper 2002-4505, August 2002.

${ }^{12}$ Liechty, D. S., Hollis, B. R., and Edquist, K. T., "Control Surface and Afterbody Experimental Aeroheating for a Proposed Mars Smart Lander Aeroshell," AIAA Paper 2002-4506, August 2002.

${ }^{13}$ Erickson, G.E., "Overview of Selected Measurement Techniques for Aerodynamic Testing in the NASA Langley Unitary Plan Wind Tunnel," AIAA Paper 2000-2396, June 2000.

${ }^{14}$ Schwartz, R.J., Fleming, G.A., "LiveView3D: Real Time Data Visualization for the Aerospace Testing Environment," AIAA-2006-1388, January 2006.

${ }^{15}$ Liu, T., and Sullivan, J.P., Pressure and Temperature Sensitive Paints, Springer-Verlag, Berlin, 2005.

${ }^{16}$ Korzun, A.M., Murphy, K.J., Edquist, K.T., "Supersonic Aerodynamic Characteristics of Blunt Body Trim Tab Configurations," Accepted to AIAA 31 $1^{\text {st }}$ Applied Aerodynamics Conference, San Diego, CA, June 2013.

${ }^{17}$ Blake, W.W., Experimental Aerodynamic Characteristics of the Viking Entry Vehicle Over the Mach Range 1.5 - 10.0, NASA CR-159225, April 1971.

${ }^{18}$ Schoenenberger, M., Dyakonov, A. A., Buning, P. G., Scallion, W., and Norman, J. W. V., “Aerodynamic Challenges for the Mars Science Laboratory Entry, Descent and Landing," AIAA Paper 2009-3914, June 2009. 